\title{
Proceeding
}

Supplementary Issue: Spring Conferences of Sports Science. Costa Blanca Sports Science Week, 26-28 April 2018. Calpe. Alicante, Spain

\section{Men's triathlon correlation between stages and final result in the London 2012 Olympic Games}

\author{
ANDRÉS B. FERNÁNDEZ-REVELLES 1 , IRWIN RAMÍREZ-GRANIZO ${ }^{1}$, MANUEL CASTRO-SÁNCHEZ², \\ ROSARIO PADIAL-RUZ 3 \\ ${ }^{1}$ Department of Sport and Physical Education, University of Granada, Spain \\ ${ }^{2}$ Research Group HUM-238, University of Granada, Spain \\ ${ }^{3}$ Department of Didactics of Music, Plastic and Corporal Expression, University of Granada, Spain
}

\begin{abstract}
Introduction: Triathlon is a sport that combines three different disciplines. The most widespread triathlon is the Olympic modality, which is used in the Olympic Games, consisting of swimming $1.5 \mathrm{~km}$, cycling $40 \mathrm{~km}$ and running $10 \mathrm{~km}$. Aims: To determine the influence of the duration and order of the different stages on the final result of the men's triathlon race in London 2012 Olympic Games. Method: Data from 54 athletes who finished was analysed. Results and conclusions: The final result is not determined neither by the order of the stages, nor by their duration, the least influential discipline being Bike without correlation with result; however being the most time consuming, $53.76 \%$; the most influential stage was Run with $r s=0.913$; and $p=0.000$; and R2 $=0.833$, with $28.93 \%$ duration. Key words: OLYMPIC TRIATHLON, OLYMPIC GAMES, STAGES, COMPETITION RULES, GAME RULES, COMBINED EVENTS.
\end{abstract}

\section{Cite this article as:}

Fernández-Revelles, A.B., Ramírez-Granizo, l., Castro-Sánchez, M., \& Padial-Ruz, R. (2018). Men's triathlon correlation between stages and final result in the London 2012 Olympic Games. Journal of Human Sport and Exercise, 13(2proc), S514-S528. doi:https://doi.org/10.14198//hse.2018.13.Proc2.35

Corresponding author. Department of Sport and Physical Education, University of Granada, Spain. https://orcid.org/0000-00028089-650X

E-mail: abfr@ugr.es

Supplementary Issue: Spring Conferences of Sports Science. Costa Blanca Sports Science Week, 26-28 April 2018. Calpe. Alicante, Spain.

JOURNAL OF HUMAN SPORT \& EXERCISE ISSN 1988-5202

(c) Faculty of Education. University of Alicante

doi: 10.14198/jhse.2018.13.Proc2.35

S514 $|2018|$ Proc2 | VOLUME 13

(c) 2018 University of Alicante 


\section{INTRODUCTION}

Since the beginning of this millennium, the practice of sports at all levels has become much more popular, in non-professional competitions, middle and long distance sporting events are achieving great success. Among these sporting events, those taking place in different areas are also becoming popular, even in natural landscapes, such as marathons, half marathons, $10 \mathrm{~km}$ running races, mountain bike routes, descents and also those performed in water such as swimming in beaches, reservoirs, etc.

Beside these sporting events others have emerged combining different disciplines, such as triathlon, which combines swimming, followed by cycling and finishing with running. To these three segments or stages in the race, transitions between them have to be added. Following the rules of the game established by triathlon regulations (ITU International Triathlon Union, 2017b) the final results of the race are obtained by the sum of time spent in the three stages plus the sum of the transitions between them, the athlete who has finished the event in the shortest time becoming the winner and establishing subsequently the order of the classification.

We will name the classification established by the arrival at the finish line in the last stage or the classification in each of the stages ranking (Fernandez-Revelles, 2012, 2014, 2017, 2018; Fernandez-Revelles, EspejoGarcés, Ubago-Jiménez, \& Chacón-Cuberos, 2018; Fernandez-Revelles, Ubago-Jiménez, et al., 2018). Ranking acquires greater importance in a competition such as a championship or a league made up of different triathlon disciplines, where the classification or ranking in each stage gives the athlete a score which is added to the previous one, becoming the winner of that championship the athlete who achieves the highest score.

Triathlon has different categories depending mainly on age and on the distance in each stage and overall. In all of them the following stages are combined in this order Swim, T1: transition 1, Cyclo or Bike, T2: Transition 2 and Run. By adding the different times in each segment we obtain the Total Time of the triathlon race. In order to refer to the different stages more easily we will call them Swim, Cyclo or Bike interchangeably and Run and the two phases of transition will be referred to as Transitions, and the final result Total Time.

The most widely spread triathlon is the Olympic modality, where the stages are Swim $1.5 \mathrm{~km}$; Bike $40 \mathrm{~km}$ and Run $10 \mathrm{~km}$. After its approval to be part of the Olympic Games in 1994, the first time a triathlon competition was performed in the Olympic Games was in Sidney 2000 in both male and female categories, as indicated by the ITU International Triathlon Union (2017b).

All participants in triathlon competitions follow the same game rules, with the fixed distances aforementioned. However, no time patterns exist for the accomplishment of each of the stages and the relation between them. Given that triathlons are performed through different outdoor routes, with changeable conditions, the time consumed by the athlete in each stage is different.

Triathlon is enriched by the diversity of athletes and differences between the stages. Although the rules of the game are the same for everybody and are aimed at giving equal possibilities of success to all triathletes, certain mechanisms and elements in the game, such as intensity of the race or adaptation of the route to the different profiles of the athletes can influence success (Zapico, Benito, Diaz, Ruiz, \& Calderon, 2014).

The fact that small variations to the game rules can be made can benefit some competitors adapting the race to a certain population (Méndez-Giménez \& Fernández-Río, 2011). 
It is important to analyse triathlon in more depth as recent studies show (Fernandez-Revelles, 2017; Fernandez-Revelles, Espejo-Garcés, et al., 2018; Fernandez-Revelles, Ubago-Jiménez, et al., 2018) specifically men's triathlon in Sidney 2000 and Athens 2004 Olympic Games. These studies show the contrast between duration of the stages and the influence in the final result and even the differences regarding influence in the final result between both events. Likewise, the influence of the order of the stages on the race is not clear. These reasons justify the increase of studies regarding this matter.

Being so many and so different the elements of the game involved in this type of competition, it should be analysed if there is certain connection with specific profiles of participants who could be favoured as indicated by (Nacke, Bateman, \& Mandryk, 2011; Rivas et al., 2015; Tondello et al., 2016).

Triathlon races are very demanding competitions and in order to achieve optimal skills for the competition, long periods of physical training are required, besides technical, psychological and strategic training. A suitable planning of all those different elements is required regarding different needs such as strength and physiological aspects (Bentley, Wilson, Davie, \& Zhou, 1998), power (Bernard et al., 2009), biomechanical aspects, (Le Meur et al., 2013), and cognitive and psychological aspects (Jaenes Sánchez, Peñaloza Gómez, Navarrete Dueñas, \& Bohórquez Gómez-Millán, 2012; Leruite, Morente-Sánchez, Martos, Girela, \& Zabala, 2016). Knowing the relation between each of the stages, and between each stage and final result is very important in order to create a suitable training plan focusing on resistance (Bentley, Millet, Vleck, \& McNaughton, 2002; Ramos-Campo, Martínez, Esteban, Rubio-Arias, \& Jiménez, 2016).

Other elements exist which, although being also possible to plan, they are less predictable and can also alter the athlete's performance. These are the conditions of the route and elements related to the place where the competition takes place. Therefore, we have to bear in mind if the competition is located in tropical areas or of great humidity (Hue, 2011), or in utterly cold areas (Dallam, Jonas, \& Miller, 2005), or if the conditions of the trial will generate excessive corporal temperature (Kerr, Trappe, Starling, \& Trappe, 1998). These aspects will be also connected with the planning of nutrition (Jeukendrup, Jentjens, \& Moseley, 2005) and hydration (Noakes, 2007).

Another important aspect in the development of the event and that can also alter the performance of each triathlete are the different situations that can arise during the course of the event, such as drafting during the Bike stage (Etxebarria, D'Auria, Anson, Pyne, \& Ferguson, 2014; Hausswirth \& Brisswalter, 2008; Millet \& Vleck, 2000; Peeling \& Landers, 2009). Due to incidents such as drafting each triathlete knows its own features and its own possibilities in each stage, issues that are going to influence their strategies during the race (Abbiss \& Laursen, 2008; Atkinson \& Brunskill, 2000; Hausswirth \& Brisswalter, 2008; Johnson et al., 2015; Le Meur et al., 2009).

A very common situation in triathlon competitions is that the athlete perceives exertion during a certain stage, subsequently saving energy in the next phase in order to prevent total exhaustion (Bonacci, Vleck, Saunders, Blanch, \& Vicenzino, 2013). The strategies between stages or within each stage are going to depend on the athlete's efficiency of performance influenced by the type of training and its characteristics (Hausswirth \& Brisswalter, 2008; Hausswirth, Le Meur, Bieuzen, Brisswalter, \& Bernard, 2010; Le Meur et al., 2011; Peeling \& Landers, 2009).

In order to be able to introduce improvements in the training of the different triathlon disciplines, in the strategic planning of it or in any other elements related to triathlon, we need to delve into the development of the race, study the relations between the stages and between stages and final result. 


\section{Aim}

The aim of this study is to determine, regarding final results of the men's triathlon in London 2012 Olympic Games, the influence of duration, order of the stages and which stage is the most influential.

\section{MATERIAL AND METHOD}

\section{Collection of data}

Collection of data for research was structured regarding patterns used by (Fernandez-Revelles, 2012, 2014, 2017, 2018; Fernandez-Revelles, Espejo-Garcés, et al., 2018; Fernandez-Revelles, Ubago-Jiménez, et al., 2018). The procedure consists in introducing in a spread sheet all the data which coincide with the search in the database (Fernandez-Revelles, 2013; Fernandez-Revelles et al., 2009), having searched the topics "2008", "men", "triathlon", and downloading the official results of the competition found in (ITU International Triathlon Union, 2017a).

\section{Sample}

The sample used in the study is the whole census of the competition, removing the results of the stages of the triathletes who did not complete the event, finally completed by 54 triathletes (ITU International Triathlon Union, 2017a).

The data of the variables expressed in hours, minutes and seconds were transformed into seconds using an Excel table and a descriptive analysis was performed on the variables (table 1).

Table 1. Descriptors of the collected data

\begin{tabular}{lcccc}
\hline & $N$ & $\overline{\mathbf{x}}$ & $\sigma$ & $\sigma^{2}$ \\
\hline Swim 2012 Men & 54 & 1073.74 & 37.749 & 1424.950 \\
Bike 2012 Men & 54 & 3553.80 & 27.470 & 754.590 \\
Run 2012 Men & 54 & 1911.91 & 91.056 & 8291.104 \\
Transitions 2012 Men & 54 & 70.15 & 3.950 & 15.6 \\
Total Time 2012 Men & 54 & 6609.09 & 119.562 & 14295.029 \\
\hline
\end{tabular}

Likewise using Excel and its equations we organise the five variables hierarchically regarding times for each of them in order to obtain the corresponding ranking for each variable, procedure also used in previous works (Fernandez-Revelles, 2012, 2014, 2017, 2018; Fernandez-Revelles, Espejo-Garcés, et al., 2018; FernandezRevelles, Ubago-Jiménez, et al., 2018).

\section{Statistical analysis}

Variables were exported from Excel to SPSS 24 in order to carry out the following procedure:

The percentage of time consumed in each segment was calculated after adding the times of the variables.

In order to determine the connection with the final result of each stage, Spearman's rank correlation was used between final ranking and ranking of the stages (table 2). 
In order to determine the relationship between the rankings of the different stages we also used Spearman's rank correlation (table 3).

Table 2. Parameters of Spearman's rank correlation between ranking of the stages and final ranking

\begin{tabular}{lccccc}
\hline & $\boldsymbol{N}$ & $\boldsymbol{r}_{\boldsymbol{s}}$ & $\boldsymbol{Z}$ & $\boldsymbol{p}$ & $\boldsymbol{R}^{\mathbf{2}}$ \\
\hline Swim 2012 Men & 54 & $0.627^{* *}$ & 4.565 & 0.000 & 0.393 \\
Bike 2012 Men & 54 & $0.282^{*}$ & 2.053 & 0.039 & 0.080 \\
Run 2012 Men & 54 & $0.913^{* *}$ & 6.647 & 0.000 & 0.834 \\
Transitions 2012 Men & 54 & $0.443^{\star *}$ & 3.225 & 0.001 & 0.196 \\
\hline
\end{tabular}

** Significant correlation in level $p<0.01$

* Significant correlation in level $p<0.05$

Table 3. Parameters of Spearman's rank correlation between ranking and stages

\begin{tabular}{lccccc}
\hline & $\boldsymbol{N}$ & $\boldsymbol{r}_{\boldsymbol{s}}$ & $\boldsymbol{Z}$ & $\boldsymbol{p}$ & $\boldsymbol{R}^{\mathbf{2}}$ \\
\hline Swim-Bike 2012 Men & 54 & -0.34 & -2.475 & 0.808 & 0.116 \\
Swim-Run 2012 Men & 54 & $0.396^{* *}$ & 2.883 & 0.003 & 0.157 \\
Swim-Transitions 2012 Men & 54 & 0.161 & 1.172 & 0.244 & 0.026 \\
Bike-Run 2012 Men & 54 & 0.081 & 0.590 & 0.562 & 0.007 \\
Bike-Transitions 2012 Men & 54 & -0.119 & -0.866 & 0.392 & 0.014 \\
Run-Transitions 2012 Men & 54 & $0.472^{\star *}$ & 3.436 & 0.010 & 0.223 \\
\hline
\end{tabular}

${ }^{* *}$ Significant correlation in level $p<0.01$

* Significant correlation in level $p<0.05$

Finally, in order to illustrate the study different figures were created, and in addition to finding parameter $Z$ of linear regression, the coefficient of linear determination $R^{2}$ was also found in order to calculate percentage of influence.

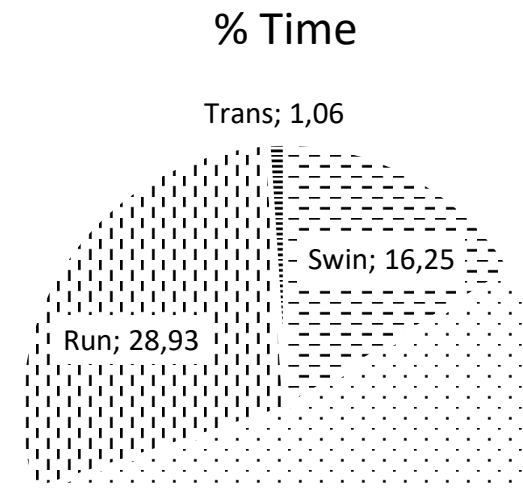

Bike; 53,76

Figure 1. Percentage of time of each stage regarding total time of the event. 


\section{RESULTS}

Results show, (figure 1) that more than $53 \%$ of the time consumed in the race was used in the Bike stage, using a little more than $28 \%$ Run and only $16.25 \%$ Swim.

The results of Spearman's correlations (table 2) show correlation between all the stages and Total Time (figures 2, 3, 4 and 5) and a very high correlation between Run and Total Time with rs= 0.993; $p=0.000$; and coefficient of linear determination R2 $=0.834$; (figure 4). There is also a moderate correlation between Transitions and Total Time (figure 5) with $r s=0.443 ; p=0.001$; and coefficient of linear determination R2= 0.196. It must be highlighted that there is a minor correlation between Bike and Total Time with $r s=0.282$; $p=0.001$; and coefficient of linear determination R2=0.080 (figure 3).

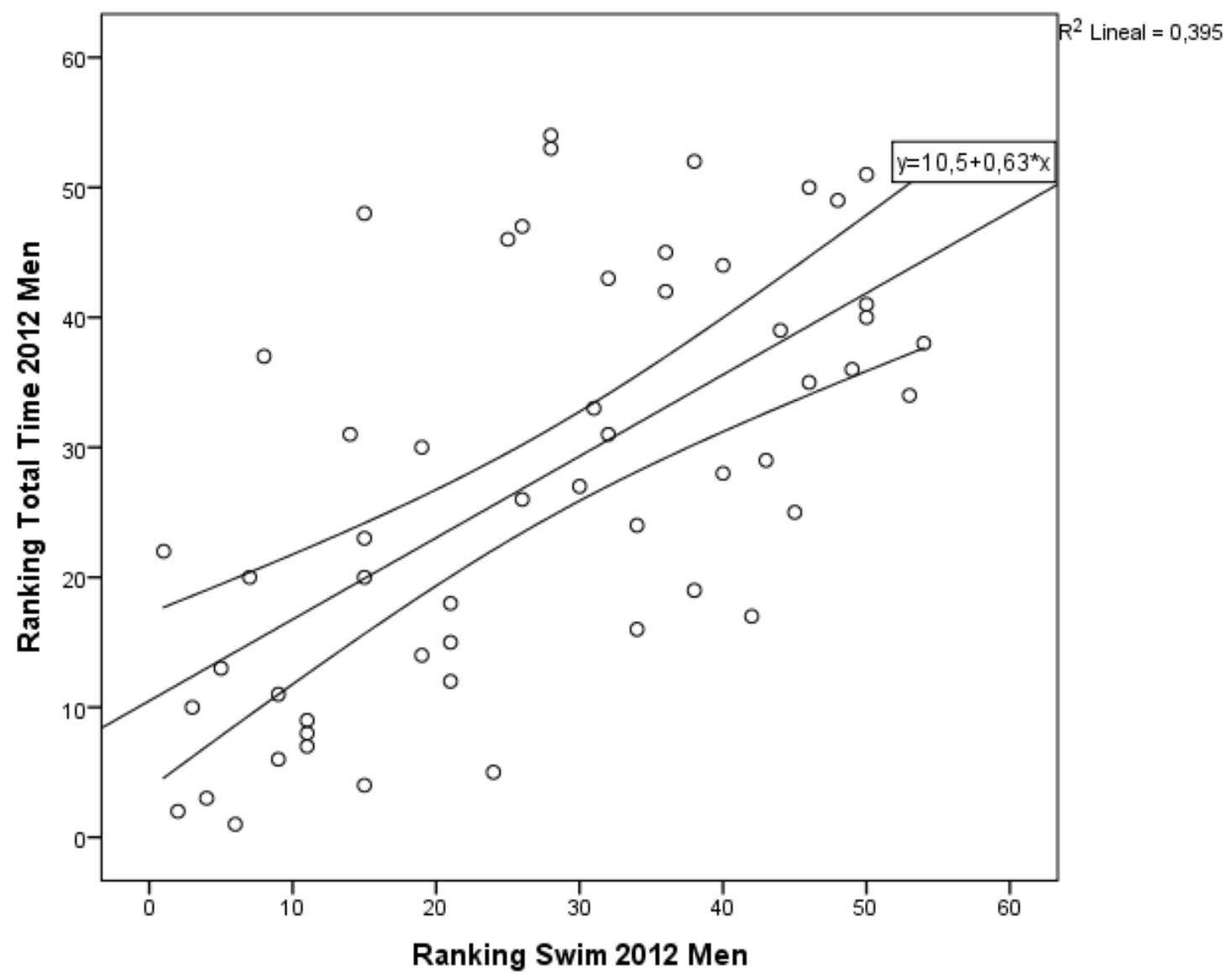

Figure 2. Relation between Swim and Total Time rankings

The results of Spearman's Correlations (table 3), show a moderate correlation between Swim and Run stages (figure 6) with $r_{s}=0.396 ; p=0.003$; and coefficient of linear determination $R^{2}=0.157$; and also a moderate correlation between Run and Transitions (figure 7) with $r_{s}=0.472 ; p=0.010$; and coefficient of linear determination $R^{2}=0.223$. There is no correlation between the other stages. 


\section{DISCUSSION}

Results show that time used in each of the segments of the race is very different, and although some stages use up more time, there is no connection between that and the influence on the ranking of that stage and final result (table2 and figure 8). This result is similar to that found in Sydney 2000 Olympic Games (Fernandez-Revelles, 2017, 2018), and Beijing 2008 (Fernandez-Revelles, Ubago-Jiménez, et al., 2018), being Run stage the most influential in Sydney 2000 with $85.9 \%$, and Bike stage exerting a minor $5.1 \%$ influence. In Beijing 2008 (Fernandez-Revelles, Ubago-Jiménez, et al., 2018) those differences increase exerting Run stage $98.24 \%$ influence (figure 4 ) in contrast to a minor $0.23 \%$ influence of Bike stage (figure 3 ), despite percentage of time used in those phases being $30.21 \%$ for Run and $52.55 \%$ for Bike.

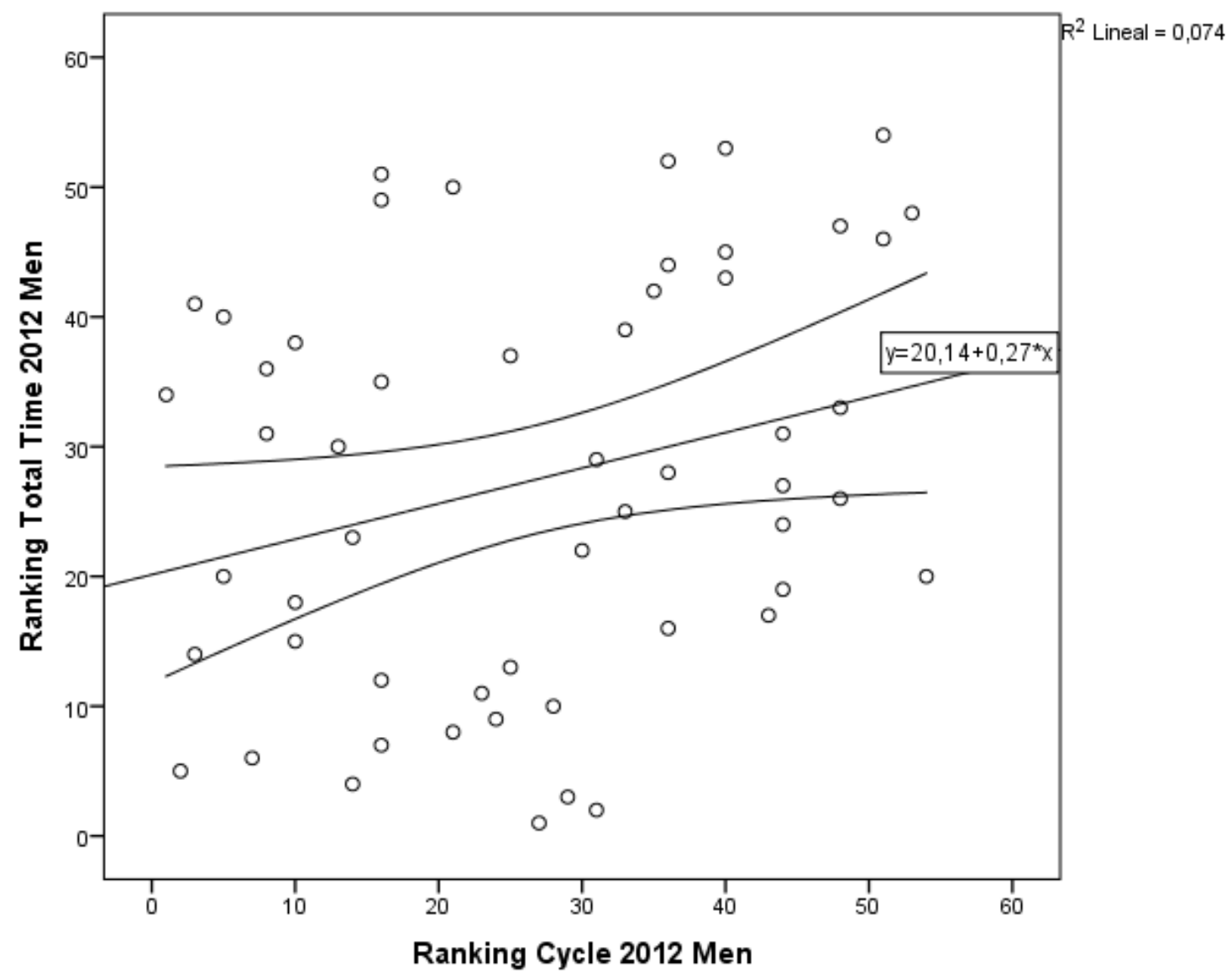

Figure 3. Relation between Cycle or Bike and Total Time rankings

However, it is a completely different result to the one shown by (Fernandez-Revelles, Espejo-Garcés, et al., 2018) in Athens 2004 triathlon where there is a directly proportional relationship between time consumed in Bike stage and the influence of the ranking of this stage on final result. In Athens 2004 the percentage of time used in the stages is Transitions 0.53\%; Swim 15.70\%; Run 29.41\%; and Bike $54.36 \%$; and the influence of the ranking of each stage on Total Time ranking is Transitions 9.97\%; Swim 17.75\%; Run 60.81\%; and Bike $76.20 \%$. 


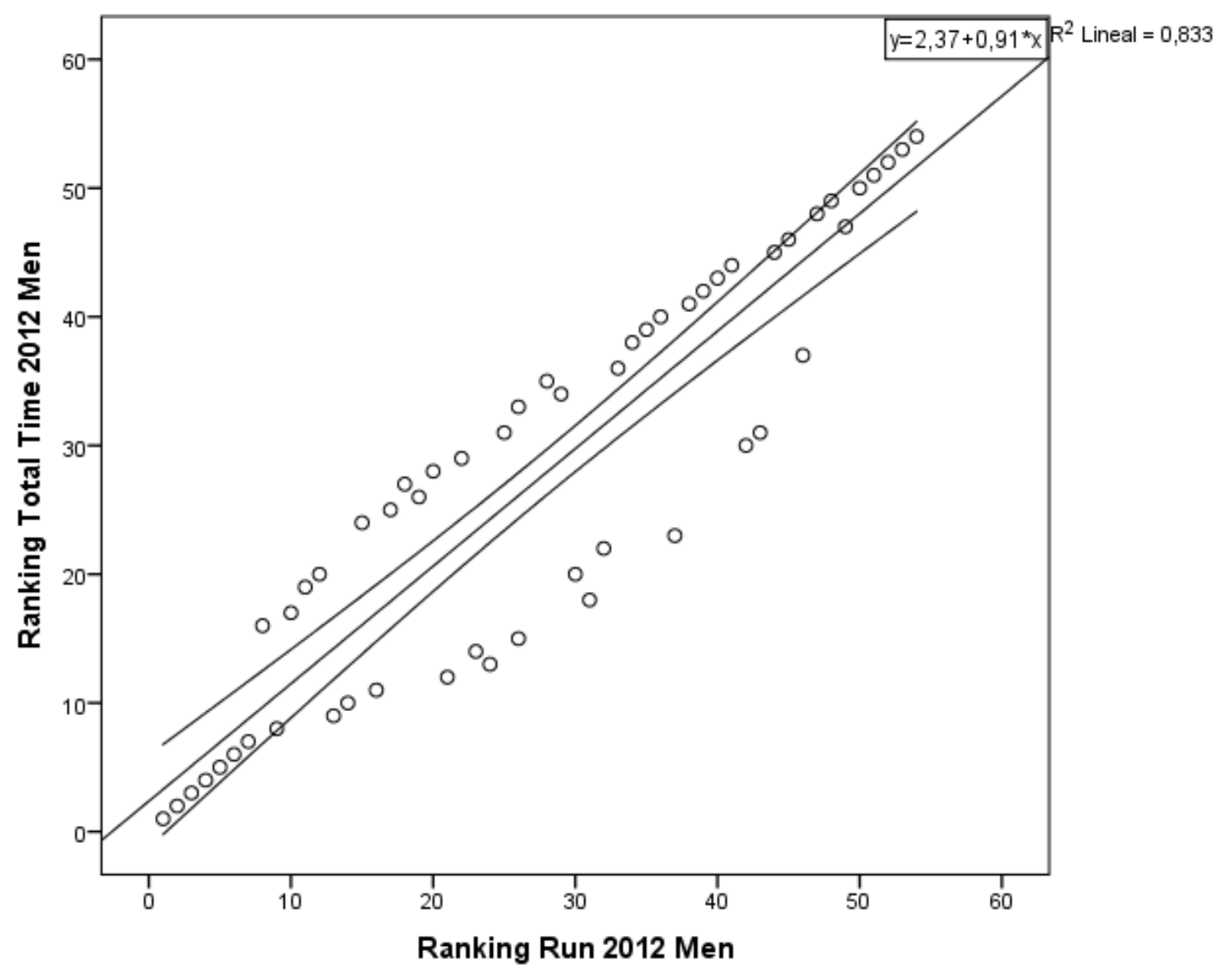

Figure 4. Relation between Run and Total Time rankings

The results of Total Time ranking in Sydney 2000, Beijing 2008 and London 2012 triathlons could be influenced by the ordering of stages due to the great influence exercised by Run with an $85.90 \%$ in Sydney, $98.24 \%$ in Beijing and an $83.34 \%$ in London, however, that is not the case since the ranking of Swim stage is lower in all of them than the following Bike stage. These results are similar to those of triathlon in Sydney 2000 Olympic Games, Beijing 2004 and the ones in London 2012. The influence of the Transition stage in London 2012 must be highlighted (figure 5) with a 19.6\% in relation to Total Time ranking. 


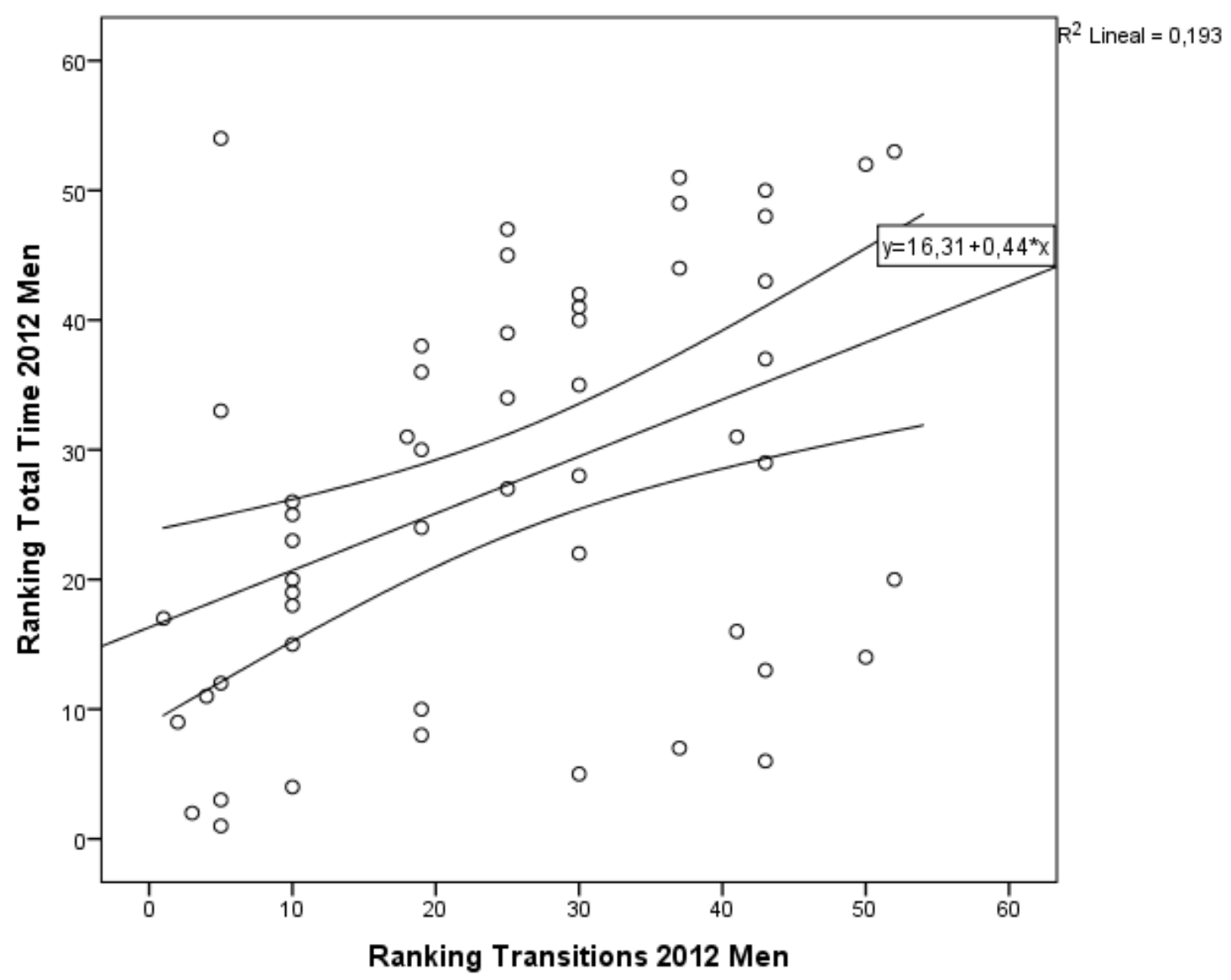

Figure 5. Relation between Transitions and Total Time rankings

Rankings of the stages and Total Time ranking of triathlons in Sydney 2000 Olympic Games (FernandezRevelles, 2017, 2018), Athens 2004 (Fernandez-Revelles, 2017) and Beijing 2008 (Fernandez-Revelles, Ubago-Jiménez, et al., 2018) show very different results. However, we can also find similarities such as time consumed in each stage. Swim stage having used $16.14 \%$ of the time in Sydney $2000,15.70 \%$ in Athens 2004, 16.40\% in Beijing 2008 and $16.25 \%$ in London 2012. Bike stage having used $53.15 \%$ of the time in Sydney 2000, 54.36\% in Athens 2004, 52.55\% in Beijing 2008 and 53.76\% in London 2012. Run phase having used $30.07 \%$ of the time in Sydney 2000, 29.41\% in Athens 2004, 30.21\% in Beijing 2008 and $28.93 \%$ in London 2012. Transitions have used $0.64 \%$ of the time in Sydney $2000,0.53 \%$ in Athens $2004,0.84 \%$ in Beijing 2008 and $1.06 \%$ in London 2012. We could summarize this saying that time consumed in the different stages of the studied triathlons is approximately $16 \%$ Swim, 53\% Bike, 30\% Run and the rest that does not reach $1 \%$ Transitions. 


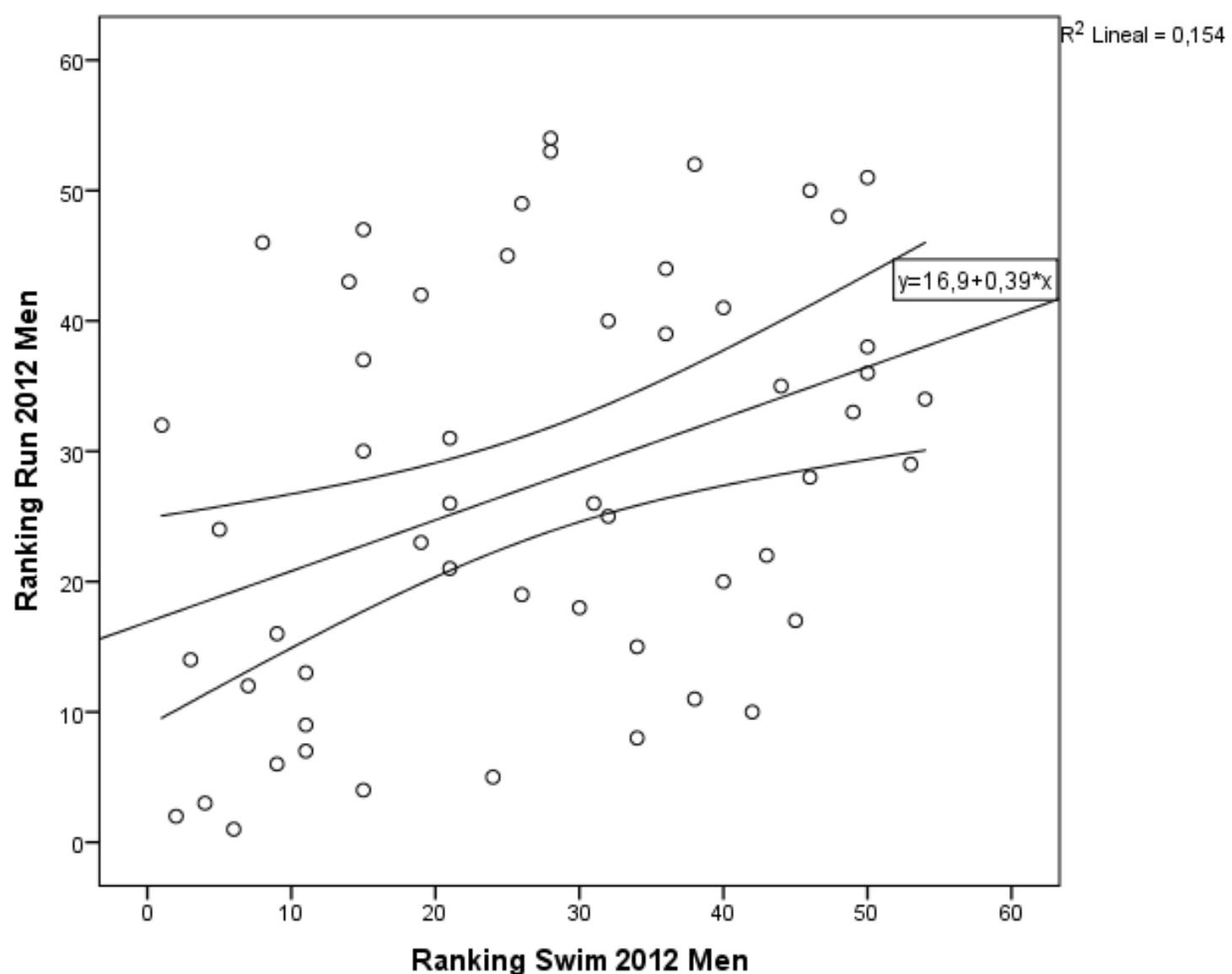

Figure 6. Relation between Swim and Run rankings

Analysing the relation of ranking correlations between stages we find that Swim and Bike in Beijing 2008 (figure 6) have an inversely proportional relation with correlation $r s=-0.931$; and $p=0.000$; which can indicate that greater exertion during the Swim stage can imply resting during the following Bike stage. Result that was very noticeable in Beijing 2008 and very similar to Sydney 2000 with $r_{s}=-0.480$; and $p=0.000$; but very different to the result in Athens 2004, showing a directly proportional correlation, although low, of $r_{s}=0.311$; and $p=0.038$. In London 2012, as we can see, similar results to those in Sydney and Beijing have reappeared. 


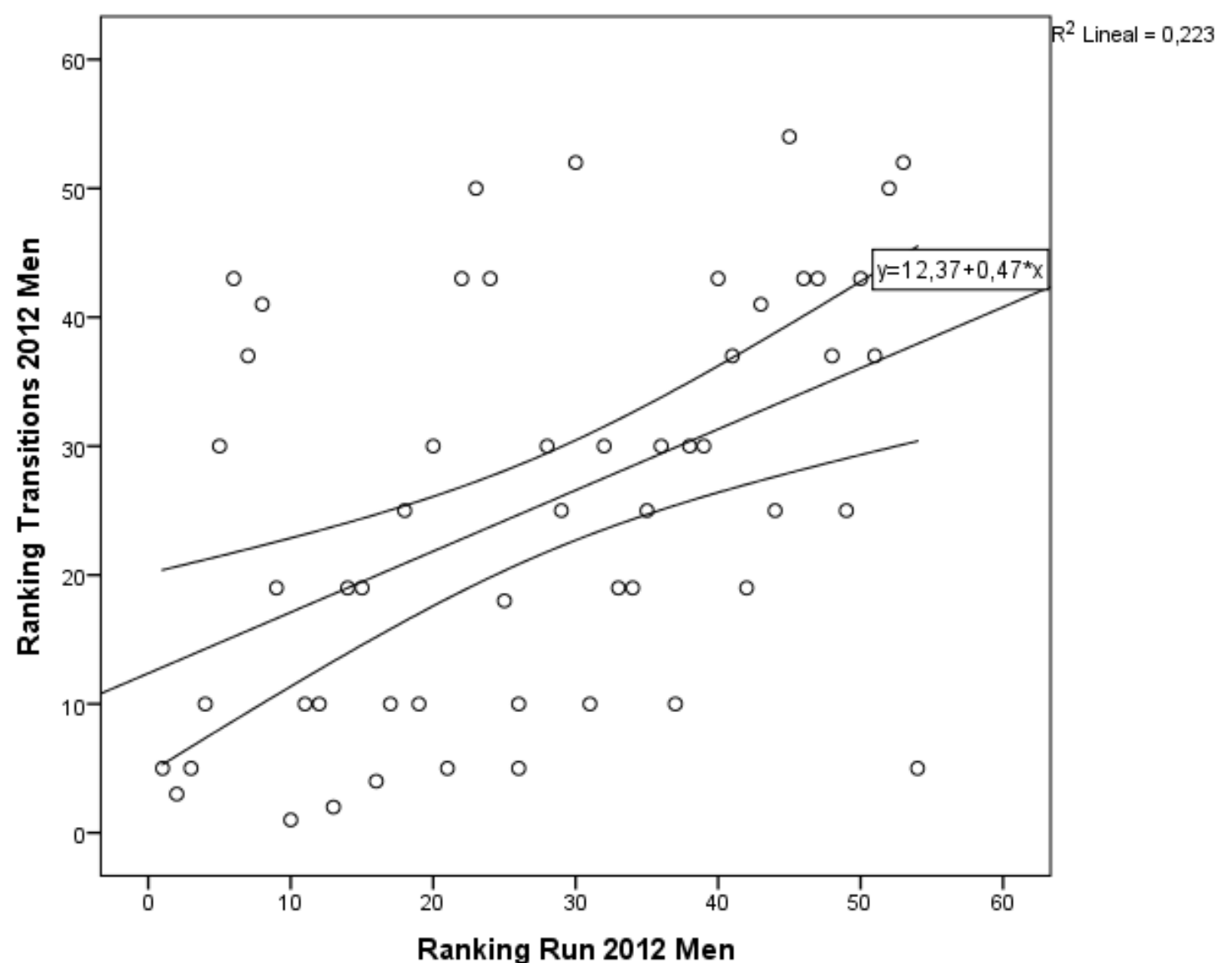

Figure 7. Relation between Run and Transitions rankings

In London 2012 there is a correlation between stages $r s=0.396$; and $p=0.003$ (figure 7) similar to that in Beijing 2008 and Sydney. In Beijing 2008 no correlations exist between stages except the moderate correlation existing between Run and Transitions with $r s=0.409$; and $p=0.003$; similar results to those regarding correlation between Transitions and Total Time which can imply greater predisposition in the preparation of transitions of those who are focusing on a final victory. This result is also similar to the one found in Sydney 2000 with $r_{s}=0.391$; and $p=0.006$. 


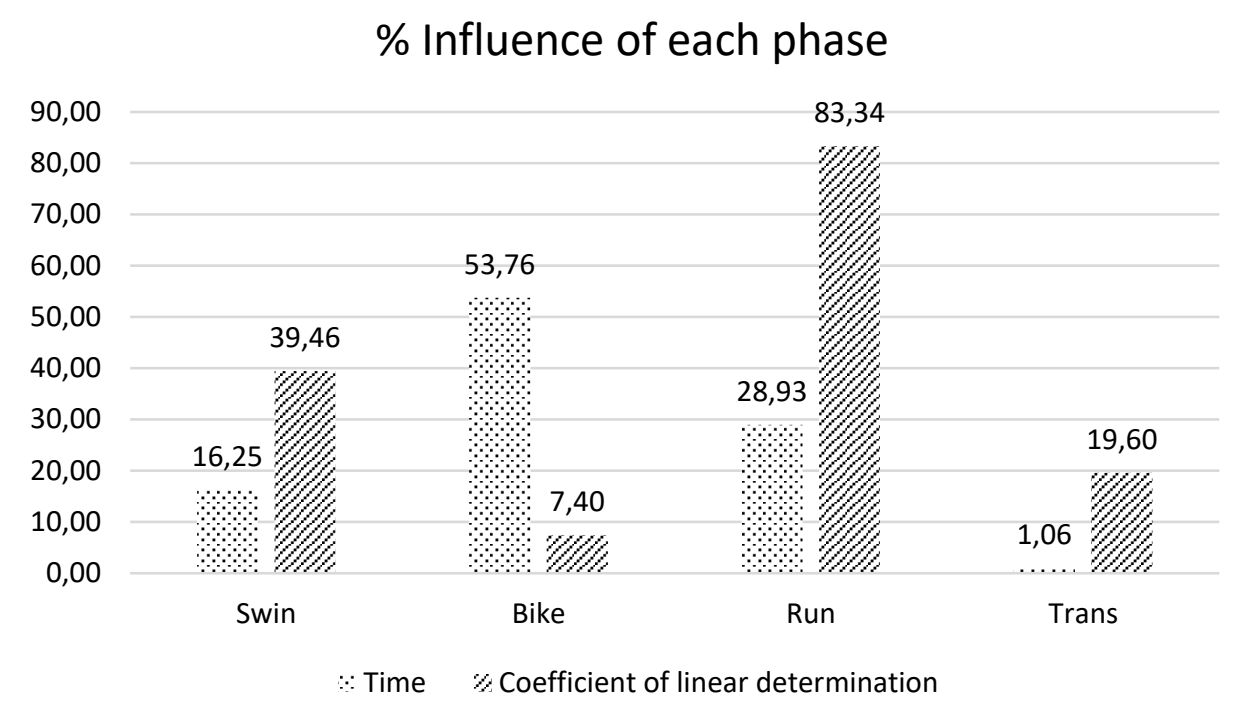

Figure 8. Influence of each stage on the overall event depending on percentage of time consumed in each stage and on percentage of final ranking determined by each stage regarding coefficient of linear determination $\mathrm{R} 2$.

\section{Suggestions for future research studies}

This kind of studies have been substantiated by the contrast between the similarity of time consumed during the different stages in the different triathlons and on the other hand the big difference between rankings of the stages and Total Time ranking.

Along the same lines, we should continue studying the patterns followed by these disciplines in the Olympic Games, and subsequently other types of triathlons in their different categories, ages, distances, genders, etc. It would also be interesting to continue working in order to find common conclusions that might suggest the modification of some of the rules of the competition or include correcting factors.

\section{CONCLUSIONS}

The final results of the men's triathlon in Beijing 2008 Olympics is not determined neither by order of the stages, nor by duration of them. The least influential stage on the final result has been Bike despite being the greater time consuming one, resulting Run the most influential despite being the last stage of the event.

\section{REFERENCES}

Abbiss, C. R., \& Laursen, P. B. (2008). Describing and understanding pacing strategies during athletic competition. Sports Medicine, 38(3), 239-252. https://doi.org/10.2165/00007256-200838030-00004

Atkinson, G., \& Brunskill, A. (2000). Pacing strategies during a cycling time trial with simulated headwinds and tailwinds. Ergonomics, 43(10), 1449-1460. https://doi.org/10.1080/001401300750003899

Bentley, D. J., Millet, G. P., Vleck, V. E., \& McNaughton, L. R. (2002). Specific aspects of contemporary triathlon - Implications for physiological analysis and performance. Sports Medicine, 32(6), 345-359. https://doi.org/10.2165/00007256-200232060-00001 
Bentley, D. J., Wilson, G. J., Davie, A. J., \& Zhou, S. (1998). Correlations between peak power output, muscular strength and cycle time trial performance in triathletes. Journal of Sports Medicine and Physical Fitness, 38(3), 201-207.

Bernard, T., Hausswirth, C., Le Meur, Y., Bignet, F., Dorel, S., \& Brisswalter, J. (2009). Distribution of Power Output during the Cycling Stage of a Triathlon World Cup. Medicine and Science in Sports and Exercise, 41(6), 1296-1302. https://doi.org/10.1249/MSS.0b013e318195a233

Bonacci, J., Vleck, V., Saunders, P. U., Blanch, P., \& Vicenzino, B. (2013). Rating of perceived exertion during cycling is associated with subsequent running economy in triathletes. Journal of Science and Medicine in Sport, 16(1), 49-53. https://doi.org/10.1016/j.jsams.2012.04.002

Dallam, G. M., Jonas, S., \& Miller, T. K. (2005). Medical considerations in triathlon competition Recommendations for triathlon organisers, competitors and coaches. Sports Medicine, 35(2), 143161. https://doi.org/10.2165/00007256-200535020-00004

Etxebarria, N., D'Auria, S., Anson, J. M., Pyne, D. B., \& Ferguson, R. A. (2014). Variability in Power Output During Cycling in International Olympic-Distance Triathlon. International Journal of Sports Physiology and Performance, 9(4), 732-734. https://doi.org/10.1123/ijspp.2013-0303

Fernandez-Revelles, A. B. (2012). ABFR-Index: correlación entre producción científica y Juegos Olímpicos 2008. Habilidad Motriz, 38, 51-57. doi: http://hdl.handle.net/10481/29518

Fernandez-Revelles, A. B. (2013). Modelo matemático de ley de potencias aplicado al maratón. Habilidad Motriz, 41, 12-20. doi: http://hdl.handle.net/10481/29518

Fernandez-Revelles, A. B. (2014). ABFR-Index: correlation between "soccer" scientific production and ranking. Revista Internacional De Medicina Y Ciencias De La Actividad Fisica Y Del Deporte, 14(56),

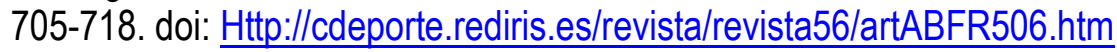

Fernandez-Revelles, A. B. (2017). Correlation between phases and final result in Men's triathlon competition at the Olympic Games in Sydney 2000. Retos-Nuevas Tendencias En Educacion Fisica $\begin{array}{llll}\text { Deporte } & Y & \text { Recreacion(32), doi: }\end{array}$ http://recyt.fecyt.es/index.php/retos/article/download/52952/33666

Fernandez-Revelles, A. B. (2018). Infographic. Correlation between phases and final result in Men's triathlon competition at the Olympic Games in Sydney 2000. British Journal of Sports Medicine(Accepted). https://doi.org/10.1136/bjsports-2018-099225

Fernandez-Revelles, A. B., Espejo-Garcés, T., Ubago-Jiménez, J. L., \& Chacón-Cuberos, R. (2018). Men's triathlon correlation between the phases and the final result in the Olympic Games in Athens 2004. Journal of Sport and Health Research(Accepted).

Fernandez-Revelles, A. B., Robles, A., Dafos, J., Soto, V. M., Perez-Cortes, A. J., Latorre, P., . . . Romero, C. (2009). Physical activity: Evaluation of research in Spain. Gaceta sanitaria, 23, 204-204.

Fernandez-Revelles, A. B., Ubago-Jiménez, J. L., Padial-Ruz, R., Castro-Sánchez, M., VicianaGarófano, V., \& Puertas-Molero, P. (2018). Men's triathlon correlation between the phases and result in the Olympic Games in Beijing 2008. SPORT TK Revista Euroamericana de Ciencias del Deporte(Accepted).

Hausswirth, C., \& Brisswalter, J. (2008). Strategies for Improving Performance in Long Duration Events Olympic Distance Triathlon. Sports Medicine, 38(11), 881-891. https://doi.org/10.2165/00007256200838110-00001

Hausswirth, C., Le Meur, Y., Bieuzen, F., Brisswalter, J., \& Bernard, T. (2010). Pacing strategy during the initial phase of the run in triathlon: influence on overall performance. European Journal of Applied Physiology, 108(6), 1115-1123. https://doi.org/10.1007/s00421-009-1322-0

Hue, O. (2011). The Challenge of Performing Aerobic Exercise in Tropical Environments: Applied Knowledge and Perspectives. International Journal of Sports Physiology and Performance, 6(4), 443-454. https://doi.org/10.1123/ijspp.6.4.443 
ITU International Triathlon Union. (2017a). ITU Competition Results. Retrieved 9-09, 2016, from http://www.triathlon.org/results

ITU International Triathlon Union. (2017b, Mayo-2017). ITU Competition Rules. Retrieved 9-09, 2016, from http://www.triathlon.org/about/documents

Jaenes Sánchez, J. C., Peñaloza Gómez, R., Navarrete Dueñas, K. G., \& Bohórquez Gómez-Millán, M. R. (2012). Ansiedad y autoconfianza precompetitiva en triatletas. Revista iberoamericana de psicología del ejercicio y el deporte, 7(1), 113-124.

Jeukendrup, A. E., Jentjens, R., \& Moseley, L. (2005). Nutritional considerations in triathlon. Sports Medicine, 35(2), 163-181. https://doi.org/10.2165/00007256-200535020-00005

Johnson, E. C., Pryor, J. L., Casa, D. J., Belval, L. N., Vance, J. S., DeMartini, J. K., . . Armstrong, L. E. (2015). Bike and run pacing on downhill segments predict Ironman triathlon relative success. Journal of Science and Medicine in Sport, 18(1), 82-87. https://doi.org/10.1016/j.jsams.2013.12.001

Kerr, C. G., Trappe, T. A., Starling, R. D., \& Trappe, S. W. (1998). Hyperthermia during Olympic triathlon: influence of body heat storage during the swimming stage. Medicine and Science in Sports and Exercise, 30(1), 99-104. https://doi.org/10.1097/00005768-199801000-00014

Le Meur, Y., Bernard, T., Dorel, S., Abbiss, C. R., Honnorat, G., Brisswalter, J., \& Hausswirth, C. (2011). Relationships Between Triathlon Performance and Pacing Strategy During the Run in an International Competition. International Journal of Sports Physiology and Performance, 6(2), 183194. https://doi.org/10.1123/ijspp.6.2.183

Le Meur, Y., Hausswirth, C., Dorel, S., Bignet, F., Brisswalter, J., \& Bernard, T. (2009). Influence of gender on pacing adopted by elite triathletes during a competition. European Journal of Applied Physiology, 106(4), 535-545. https://doi.org/10.1007/s00421-009-1043-4

Le Meur, Y., Hausswirth, C., Natta, F., Couturier, A., Bignet, F., \& Vidal, P. P. (2013). A multidisciplinary approach to overreaching detection in endurance trained athletes. Journal of Applied Physiology, 114(3), 411-420. https://doi.org/10.1152/japplphysiol.01254.2012

Leruite, M., Morente-Sánchez, J., Martos, P., Girela, M. J., \& Zabala, M. (2016). Analysis of the Sporting Context of Spanish Female Competitive Cyclists and Triathletes. Revista Internacional De Medicina Y Ciencias De La Actividad Fisica Y Del Deporte, 16(64), 667-684.

Méndez-Giménez, A., \& Fernández-Río, J. (2011). Análisis y modificación de los juegos y deportes tradicionales para su adecuada aplicación en el ámbito educativo. Retos. Nuevas tendencias en Educación Física, Deporte y Recreación, 19, 54-58.

Millet, G. P., \& Vleck, V. E. (2000). Physiological and biomechanical adaptations to the cycle to run transition in Olympic triathlon: review and practical recommendations for training. British Journal of Sports Medicine, 34(5), 384-390. https://doi.org/10.1136/bjsm.34.5.384

Nacke, L. E., Bateman, C., \& Mandryk, R. L. (2011). BrainHex: Preliminary Results from a Neurobiological Gamer Typology Survey. In J. Anacleto, S. Fels, N. Graham, B. Kaparalos, M. S. EINasr, \& K. Stanley (Eds.), Entertainment Computing - Icec 2011 (Vol. 6972, pp. 288-293). Berlin: Springer-Verlag Berlin. https://doi.org/10.1007/978-3-642-24500-8_31

Noakes, T. D. (2007). Drinking guidelines for exercise: What evidence is there that athletes should drink "as much as tolerable", "to replace the weight lost during exercise" or "ad libitum"? Journal of Sports Sciences, 25(7), 781-796. https://doi.org/10.1080/02640410600875036

Peeling, P., \& Landers, G. (2009). Swimming intensity during triathlon: A review of current research and strategies to enhance race performance. Journal of Sports Sciences, 27(10), 1079-1085. https://doi.org/10.1080/02640410903081878

Ramos-Campo, D. J., Martínez, F., Esteban, P., Rubio-Arias, J. A., \& Jiménez, J. F. (2016). Intermittent hypoxic training and cycling performance in triathletes. Revista Internacional De Medicina $Y$ Ciencias De La Actividad Fisica Y Del Deporte, 16(61), 139-156. https://doi.org/10.15366/rimcafd2016.61.011 
Rivas, L. G., Mielgo-Ayuso, J., Norte-Navarro, A., Cejuela, R., Cabanas, M. D., \& Martinez-Sanz, J. M. (2015). Body composition and somatotype in university triathletes. Nutricion Hospitalaria, 32(2), 799807. doi: $10.3305 /$ nh.2015.32.2.9142

Tondello, G. F., Wehbe, R. R., Diamond, L., Busch, M., Marczewski, A., Nacke, L. E., \& Acm. (2016). The Gamification User Types Hexad Scale. Chi Play 2016: Proceedings of the 2016 Annual Symposium on Computer-Human Interaction in Play, 229-243. https://doi.org/10.1145/2967934.2968082

Zapico, A. G., Benito, P. J., Diaz, V., Ruiz, J. R., \& Calderon, F. J. (2014). Heart rate profile in highly trained triathletes. Revista Internacional De Medicina Y Ciencias De La Actividad Fisica Y Del Deporte, 14(56), 619-632. doi: Http://cdeporte.rediris.es/revista/revista56/artperfil505.htm

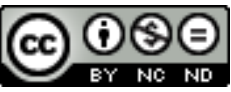

This title is licensed under a Creative Commons Attribution-NonCommercial-NoDerivs 4.0 Unported License. 